\title{
Note on Romanization
}

With only a few exceptions, the pinyin system is used to transliterate Chinese. Discretion has been left to individual authors as to whether to use pinyin or the older form of certain well-known names. These are as follows: (pinyin given first): Jiang Jieshi/Chiang Kai-shek; Hu Shi/Hu Shih; Beijing/ Peking; Beiping/Peiping; Rehe/Jehol; Chaha'er/Chahar; Xiamen/Amoy; Yangzi/Yangtze; Manzhouguo/Manchukuo. Sun Yat-sen is used rather than Sun Zhongshan. 


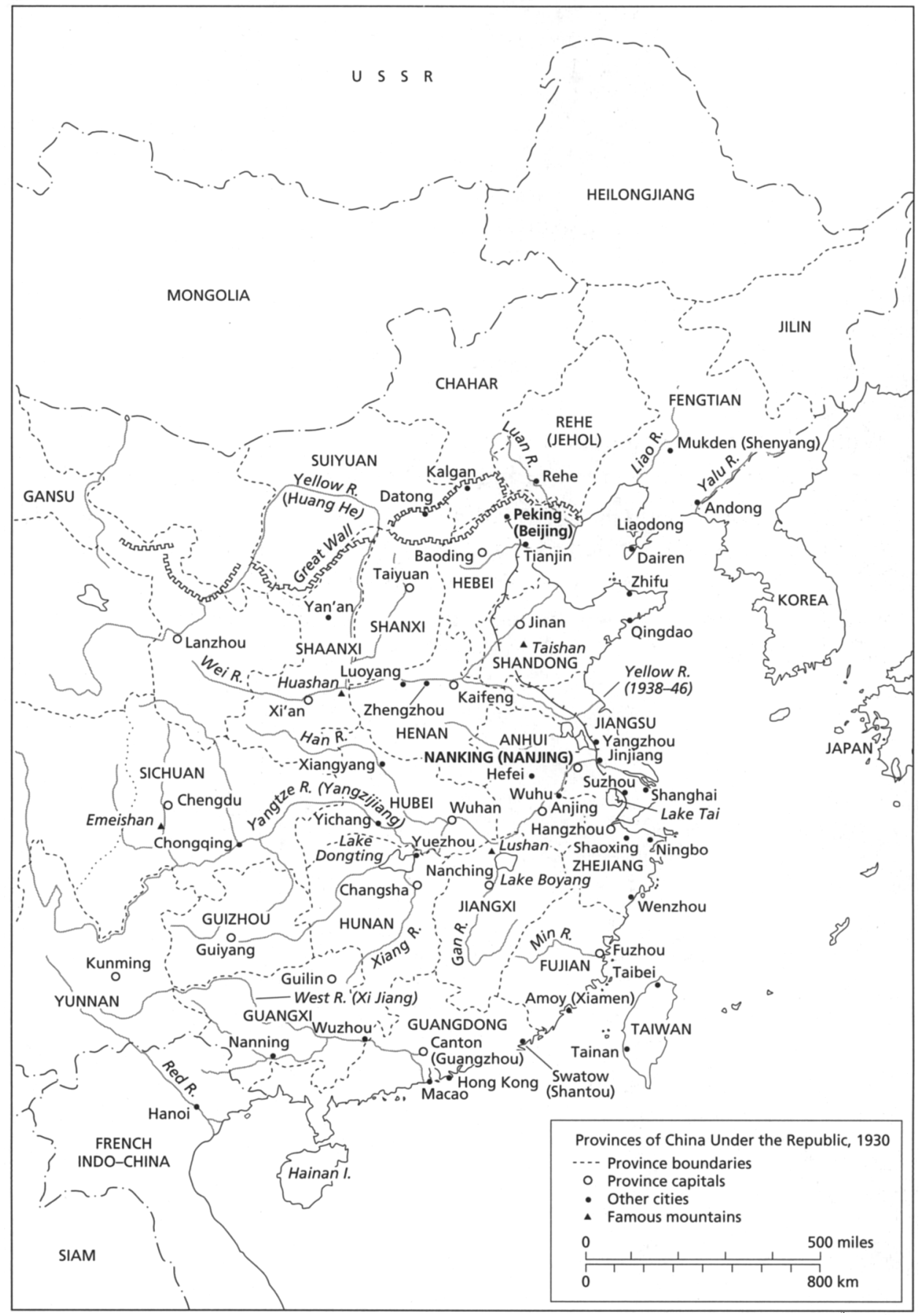

Provinces of China Under the Republic, 1930 


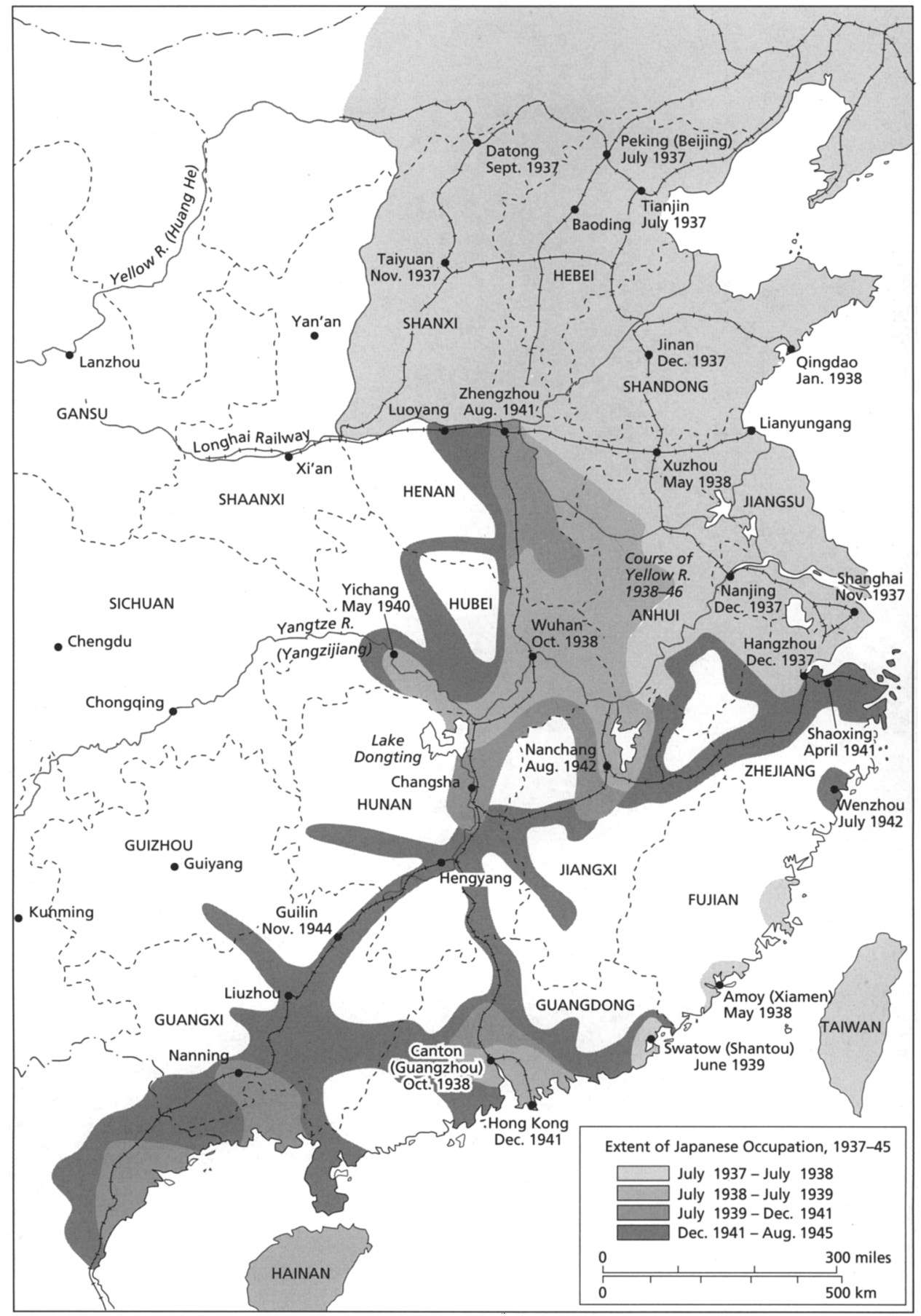

Japanese Military Occupation of China Proper 